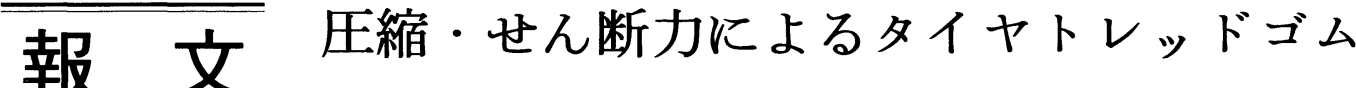 の圧力分布と浮き上がり現象
}

(平成 4 年 9 月 17 日 受理)

\begin{abstract}
赤坂 隆*·加々美 茂*・長谷川 淳* ·塩原 仁*
要旨 タイヤは走る, 曲がる, 止まるといった車の基本的性能を実現するために, 路上において常に 複雑で苛酷な変形を強いられている.タイヤの構成要素の中でもトレッド部はタイヤと路面との間の摩擦を 確保し, 有効な制動力や操縦性能を発揮させる機能を持つ.トレッドゴムが路面に接して圧縮力とせん断力 を受けると，接地端部の浮き上がり現象が起こる。このことは路面との接地面積を減少させ, 偏摩耗を生じ させる.

これまでに，この問題に対しては，実験的研究および Mooney-Rivlin の非線形フック則を用いた FEM 解 析による数值解析が行われており，接触圧分布についてはよい一致が得られている. 本研究では浮き上がり 時の臨界条件を求めるため, ゴムの非圧縮性を考慮した線形フック則に基づくェネルギー法によって，圧縮 力とせん断力を受けたゴムブロックの接地変形について近似解析を行った。 その結果, 接地圧分布ならびに 浮き上がり条件について理論解析, 数值解析および実験值の間によい一致が得られた。
\end{abstract}

\section{1. まえがき}

タイヤは走る，曲がる，止まるといった車の基 本的性能を実現するために，常に過酷で複雑な变 形を強いられている，タイヤの構成要素の中でも トレッド部は, タイヤが転動するときに路面と直 接接触する部分であり，カーカス部を保護するだ けではなく，タイヤと路面との間の摩擦を確保 し, 有効な制動力や操縦性能を発揮させる機能を もつ，そのため，トレッドゴムは車体重量による 圧縮力を受けるとともに，トレッドの表面と路面 との間には複雑な相対運動が生じ, トレッド摩耗 の原因になる.

このように, トレッドゴムは圧縮・せん断力を 受けて複雑な変形状態を呈し，遂にはゴムブロッ クの端部が浮き上がる現象が起こる。これは直接 的には接地面積の減少を招くだけでなく, 浮き上 がりに伴う動的すべりによって摩耗を生ずる.

この問題に対する解析として, トレッドゴムを 平面ひずみ問題として取扱い, Mooney-Rivlinの 非線形フック則を用いた FEM 解析結果 ${ }^{1)}$ が報告 されている。この結果は，接地圧分布に対して実

* 中央大学理工学部精密機械工学科 ( 京区春日1-13-27)
験値と非常によい一致を示している。しかし， FEM 解析は本来, 数值解であるため, トレッド ゴムの寸法効果に対する設計上の見通しが得難い．

そこで, 本研究では圧縮力とせん断力による浮 き上がり現象の臨界条件を求めるため, ゴムの非 圧縮性と線形フック則を考慮したエネルギー法を 用いて近似解析を行った。

\section{2. 解析}

ゴムブロックの断面が単位幅当たりの圧縮力 $P$ とせん断力 $Q$ を同時に受けたときの変形状態を Fig. 1 亿示す. この解析に拈いてはゴムブロック は垂直方向には無限に長いものと仮定し, 平面昰 問題として取り扱っている。この図において ブロックの幅を，hは高さを表しており，cは压 縮力 $P$ に伴う縮み量である。 また $\boldsymbol{\gamma}$ はブロック 全体のせん断ひずみを，入は上下面での相対的ズ レを， $\beta_{1}$ は中央面 $\mathrm{m}-\mathrm{m}^{\prime}$ の回転角を表して扣り， $M$ は上下面が平行に移動するための平衡曲げモ ーメントである。また，任意点に扔ける $x$ 方向， $y$ 方向の変位をそれぞれ $u, v$ とし, ゴムブロック は上面が剛体板に接着され，下面は単に剛体板に 接触しているものとする.

まず，任意点における変位 $u, v$ を次のように 仮定する. 


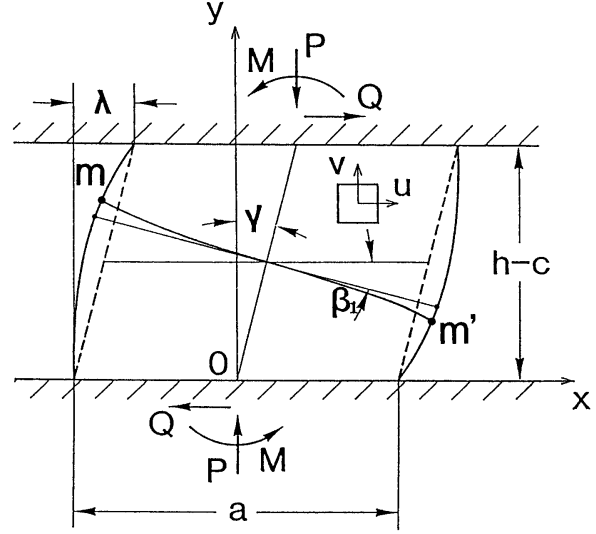

Fig. 1 Deformation of tread rubber block under compressive and shearing forces of $P$ and $Q$ respectively

$$
\begin{aligned}
& u=\alpha x \sin \frac{\pi y}{h}+\gamma y \\
& v=-c \frac{y}{h}-\left(\beta_{1} x+\beta_{2} x^{3}\right) \sin \frac{\pi y}{h}
\end{aligned}
$$

上式で， $u$ の右辺第 1 項は圧縮による幅方向の膨 らみを表し，第 2 項はせん断変形を表している. また，vの右辺第 1 項は高さ方向の一様な縮みを 表し，第 2 項は面内での回転による変位を表して いる.

ここで, 膨らみによる体積増加 $\Delta V$ は

$$
\Delta V=\alpha a \int_{0}^{h} \sin \frac{\pi y}{h} d y=2 \alpha a \frac{h}{\pi}
$$

となる。これに対して，圧縮力による縮み量は $c$ であるから，体積の減少量 $\Delta V^{\prime}$ は

$$
\Delta V^{\prime}=a c
$$

となる。したがって，ゴムの非圧縮性より $\Delta V=\Delta V^{\prime}$ となり，cの值が次のように定められ る.

$$
c=2 \alpha \frac{h}{\pi}
$$

また，式(1)を用いることにより，ひずみ成分は次 のよらに表される。

$$
\begin{aligned}
\varepsilon_{x}= & \frac{\partial u}{\partial x}=\alpha \sin \frac{\pi y}{h} \\
\varepsilon_{y}= & \frac{\partial v}{\partial y}=-\frac{2 \alpha}{\pi}-\left(\beta_{1} x+\beta_{2} x^{3}\right) \frac{\pi}{h} \cos \frac{\pi y}{h} \\
\gamma_{x y}= & \frac{\partial u}{\partial y}+\frac{\partial v}{\partial x}=\alpha x \frac{\pi}{h} \cos \frac{\pi y}{h}+\gamma-\left(\beta_{1}+3 \beta_{2} x^{2}\right) \\
& \times \sin \frac{\pi y}{h}
\end{aligned}
$$

線形フック則は

$$
\begin{aligned}
& \sigma_{x}=2 G \varepsilon_{x}+\bar{\sigma} \\
& \sigma_{y}=2 G \varepsilon_{y}+\bar{\sigma} \\
& \tau_{x y}=G \gamma_{x y}
\end{aligned}
$$

と与えられる.ここで， $\bar{\sigma}$ は静水圧， $G$ はゴムの 横弾性係数である.

単位体積当たりのひずみエネルギー $\bar{U}$ は次式で 与えられる。

$$
\bar{U}=G\left(\varepsilon_{x}^{2}+\varepsilon_{y}^{2}+\frac{1}{2} \gamma_{x y}^{2}\right)
$$

かくて, 全ひずみェネルギー $U$ は次のように求 められる。

$$
\begin{aligned}
U= & \int_{-a / 2}^{a / 2} \int_{0}^{h} \bar{U} d x d y=G \int_{-a / 2}^{a / 2} \int_{0}^{h}\left[\alpha^{2} \sin ^{2} \frac{\pi y}{h}\right. \\
& +\left\{\frac{2 \alpha}{\pi}+\left(\beta_{1} x+\beta_{2} x^{3}\right) \frac{\pi}{h} \cos \frac{\pi y}{h}\right\}^{2} \\
& +\frac{1}{2}\left\{\alpha x \frac{\pi}{h} \cos \frac{\pi y}{h}+\gamma-\left(\beta_{1}+3 \beta_{2} x^{2}\right)\right. \\
& \left.\left.\times \sin \frac{\pi y}{h}\right\}^{2}\right] d x d y
\end{aligned}
$$

さらに，積分計算を行うと

$$
\begin{aligned}
U= & G\left[\alpha^{2}\left(\frac{a h}{2}+\frac{4 a h}{\pi^{2}}+\frac{\pi^{2}}{48} \frac{a^{3}}{h}\right)+\frac{1}{2} \gamma^{2} a h\right. \\
& -2 \gamma \frac{h}{\pi}\left(\beta_{1} a+\frac{1}{4} \bar{\beta}_{2} a\right)+\beta_{1}^{2}\left(\frac{\pi^{2}}{24} \frac{a^{3}}{h}+\frac{a h}{4}\right) \\
& +\beta_{1} \bar{\beta}_{2}\left(\frac{\pi^{2}}{80} \frac{a^{3}}{h}+\frac{1}{8} a h\right)+\bar{\beta}_{2}^{2}\left(\frac{\pi^{2}}{14 \times 64} \frac{a^{3}}{h}\right. \\
& \left.\left.+\frac{9}{320} h a\right)\right]
\end{aligned}
$$

となる。ここで， $\alpha, \gamma, \beta_{1}, \beta_{2}$ は 4 つの未定係数で ある. 特に, $\beta_{2}$ は次式に示す無次元量 $\bar{\beta}_{2}$ によっ て置き変えている.

$$
\bar{\beta}_{2} \equiv \beta_{2} a^{2}
$$

他方，外力 $P, Q$ によるポテンシャル $W$ は以下の よらに与えられる。

$$
\begin{aligned}
W & =P v(h)+Q \lambda \\
& =P 2 \alpha \frac{h}{\pi}+Q \gamma h
\end{aligned}
$$

したがって，全系ポテンシャル $\Pi=U-W$ は 4 つ の未定係数 $\alpha, \gamma, \beta_{1}, \bar{\beta}_{2}$ に対して停留性を持つこ とから次式が得られる.

$$
\frac{\partial \Pi}{\partial \alpha}=\frac{\partial \Pi}{\partial \gamma}=\frac{\partial \Pi}{\partial \beta_{1}}=\frac{\partial \Pi}{\partial \bar{\beta}_{2}}=0
$$

これから， $\alpha, \gamma, \beta_{1}, \bar{\beta}_{2}$ に対する次の 4 条件式が得 られる。 


$$
\begin{aligned}
& 2 G \alpha\left[\left(\frac{1}{2}+\frac{4}{\pi^{2}}\right) a h+\frac{\pi^{2}}{48} \frac{a^{3}}{h}\right]-2 P \frac{h}{\pi}=0 \\
& G\left[\gamma a h-2 \frac{h}{\pi}\left(\beta_{1} a+\frac{1}{4} \bar{\beta}_{2} a\right)\right]-Q h=0 \\
& G\left[-2 \gamma \frac{a h}{\pi}+\beta_{1}\left(\frac{\pi^{2}}{12} \frac{a^{3}}{h}+\frac{1}{2} a h\right)\right. \\
& \left.\quad+\bar{\beta}_{2}\left(\frac{\pi^{2}}{80} \frac{a^{3}}{h}+\frac{1}{8} a h\right)\right]=0 \\
& G\left[-\frac{1}{2} \gamma \frac{a h}{\pi}+\beta_{1}\left(\frac{\pi^{2}}{80} \frac{a^{3}}{h}+\frac{1}{8} a h\right)\right. \\
& \left.+\bar{\beta}_{2}\left(\frac{\pi^{2}}{7 \times 64} \frac{a^{3}}{h}+\frac{9}{160} a h\right)\right]=0
\end{aligned}
$$

式(11)から

$$
\alpha=\frac{P}{G a} \frac{1}{\left(\frac{\pi}{2}+\frac{4}{\pi}\right)+\frac{\pi^{3}}{48}\left(\frac{a}{h}\right)^{2}}
$$

となって， $\alpha$ は $\boldsymbol{\beta}_{1}, \overline{\boldsymbol{\beta}}_{2}$ とは無関係に定まる. 式(13)，(14)から

$$
\begin{aligned}
& \beta_{1}\left(\frac{\pi^{2}}{12} \frac{a}{h}+\frac{1}{2} \frac{h}{a}\right)+\bar{\beta}_{2}\left(\frac{\pi^{2}}{80} \frac{a}{h}+\frac{1}{8} \frac{h}{a}\right) \\
& =\gamma \frac{2}{\pi} \frac{h}{a} \\
& \beta_{1}\left(\frac{\pi^{2}}{80} \frac{a}{h}+\frac{1}{8} \frac{h}{a}\right)+\bar{\beta}_{2}\left(\frac{\pi^{2}}{448} \frac{a}{h}+\frac{9}{160} \frac{h}{a}\right) \\
& =\gamma \frac{1}{2 \pi} \frac{h}{a}
\end{aligned}
$$

式(12)より次式が得られる.

$$
Q=G a\left\{\gamma-\frac{2}{\pi}\left(\beta_{1}+\frac{1}{4} \bar{\beta}_{2}\right)\right\}
$$

接触圧 $q$ は接触面 $y=0$ に打ける圧縮応力で与え られるので $q=-\sigma_{y}(0)$ となり, 次式が得られる.

$$
\begin{aligned}
q= & -\sigma_{y}(0)=2 G\left\{\frac{2 \alpha}{\pi}+\left(\beta_{1} x+\bar{\beta}_{2} \frac{x^{3}}{a^{2}}\right) \frac{\pi}{h}\right\} \\
& -\bar{\sigma}
\end{aligned}
$$

ここで, $q$ の幅方向の積分が圧縮力 $P$ に等しいこ とから, 平均圧縮応力 $\sigma_{0}$ が次のように定義され る.

$$
\int_{-a / 2}^{a / 2} q d x=P \equiv \sigma_{0} a
$$

次(19)に式(18)に代入することにより

$$
\sigma_{0}=2 G\left(\frac{2 \alpha}{\pi}\right)-\bar{\sigma}
$$

を得る.

さらに, 式(18)と式(20)から $\bar{\sigma}$ を消去すると, 接地 圧 $q$ は次式のように書き表せる。

$$
\frac{q}{\sigma_{0}}=1+\frac{2 G}{\sigma_{0}} \frac{\pi}{h}\left(\beta_{1} x+\bar{\beta}_{2} \frac{x^{3}}{a^{2}}\right)
$$

接触圧 $q$ は 3 次曲線になる.

式(16)を形状係数 $s=a / 2 h$ を用いて書きかえると

$$
\begin{aligned}
& \beta_{1}\left(\frac{\pi^{2}}{3} s^{2}+\frac{1}{2}\right)+\bar{\beta}_{2}\left(\frac{\pi^{2}}{20} s^{2}+\frac{1}{8}\right)=\gamma \frac{2}{\pi} \\
& \beta_{1}\left(\frac{\pi^{2}}{20} s^{2}+\frac{1}{8}\right)+\bar{\beta}_{2}\left(\frac{\pi^{2}}{112} s^{2}+\frac{9}{160}\right)=\gamma \frac{1}{2 \pi}
\end{aligned}
$$

となり，式(22)を $\boldsymbol{\beta}_{1}, \bar{\beta}_{2}$ について解くと

$$
\begin{aligned}
& \beta_{1}=\frac{-0.022440 s^{2}+0.015915}{0.046366 s^{4}+0.105743 s^{2}+0.0125} \gamma \\
& \bar{\beta}_{2}=\frac{0.209443 s^{2}}{0.046366 s^{4}+0.105743 s^{2}+0.0125} \gamma
\end{aligned}
$$

と求められる.

$x$ に対する無次元座標 $\xi$ を次のように定義する.

$$
\xi=\frac{2 x}{a}
$$

また， $\rho_{1}, \rho_{2}$ を次に示すような無次元係数とする と,

$$
\beta_{1} \equiv \rho_{1} \gamma, \quad \bar{\beta}_{2} \equiv \rho_{2} \gamma
$$

見かけのせん断剛性率 $G_{\text {eff }}$ は式(17)から次のように 書ける。

$$
G_{e f f}=\frac{Q}{\gamma}=G a\left\{1-\frac{2}{\pi}\left(\rho_{1}+\frac{1}{4} \rho_{2}\right)\right\}
$$

式(21)は，最終的に次式で与えられる。

$$
\frac{q}{\sigma_{0}}=1+\frac{Q}{P} 2 \pi s \frac{\rho_{1} \xi+\frac{1}{4} \rho_{2} \xi^{3}}{1-\frac{2}{\pi}\left(\rho_{1}+\frac{1}{4} \rho_{2}\right)}
$$

かくて， $\xi=-1 て ゙ ~ q=0$ となる浮き上がり限界 $Q_{c r}$ は次式で与えられる。

$$
Q_{c r}=-\frac{P}{2 \pi s} \frac{1-\frac{2}{\pi}\left(\rho_{1}+\frac{1}{4} \rho_{2}\right)}{\rho_{1} \xi+\frac{1}{4} \rho_{2} \xi^{3}}
$$

さらに，せん断応力分布 $\tau_{x y}(y=0)$ は式(3)，(4)から 次のように求められる.

$$
\tau_{x y(y=0)}=G \gamma_{x y(y=0)}=\left(\alpha x \frac{\pi}{h}+\gamma\right) G
$$




$$
\begin{gathered}
=\frac{x}{a} \frac{P \cdot \frac{\pi}{h}}{\left(\frac{\pi}{2}+\frac{4}{\pi}\right)+\frac{\pi^{3}}{48}\left(\frac{a}{h}\right)^{2}} \\
+\frac{Q}{a} \frac{1}{1-\frac{2}{\pi}\left(\rho_{1}+\frac{1}{4} \rho_{2}\right)}
\end{gathered}
$$

これは直線分布になることを示す.

\section{3. 数値計算および考察}

数值計算に使用したゴムブロックの緒元および 荷重条件を以下に示す。

$$
\begin{gathered}
s=0.625, \quad a=0.05 \mathrm{~m}, \quad h=0.04 \mathrm{~m} \\
Q=1.13 \mathrm{kN} / \mathrm{m}, \quad P=7.5 \mathrm{kN} / \mathrm{m}, \\
10 \mathrm{kN} / \mathrm{m}, \quad 12.5 \mathrm{kN} / \mathrm{m} \\
Q=2.13 \mathrm{kN} / \mathrm{m}, \quad P=7.5 \mathrm{kN} / \mathrm{m}, \\
10 \mathrm{kN} / \mathrm{m}, \quad 12.5 \mathrm{kN} / \mathrm{m} \\
Q=3.13 \mathrm{kN} / \mathrm{m}, \quad P=7.5 \mathrm{kN} / \mathrm{m}, \\
10 \mathrm{kN} / \mathrm{m}, \quad 12.5 \mathrm{kN} / \mathrm{m}
\end{gathered}
$$

Fig. 2 に，上記寸法のゴムブロックモデルにつ いて行った FEM による解析結果1)の一例を示す. ゴムブロック左端に浮き上がり現象が見られる.

Fig. 3 は, 形状係数 $s=0.667$ のゴムブロックモ デルに対する実験結果である.FEM 解析と同様 にブロック左端に浮き上がり現象が見られる.

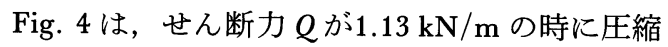
力 $P$ を $7.5 \mathrm{kN} / \mathrm{m}, 10 \mathrm{kN} / \mathrm{m}, 12.5 \mathrm{kN} / \mathrm{m}$ と変化さ せた場合の接地圧 $q$ の分布を示したものである. 実線は本解析結果を, 点線は FEM による計算結 果を，さらに○， $\triangle ， \square$ 実験值を示している. なお, 実験値は接触部の 3 か所に設置した圧力七 ンサーによる実測値である. 実験值と本解析結果 はかなりよく対応しているといえる。

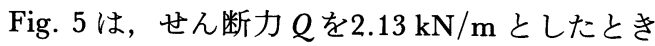
の解析結果である. この場合, 実験值と理論結果 は圧縮力 $P$ が小さいときはかなりよい対応を示 すが，Pが高くなると多少のズレが現れている. しかし，傾向的には一致していると考えられる.

Fig. 6 は，せん断力 $Q を 3.13 \mathrm{kN} / \mathrm{m}$ にした時の 結果である.この場合も Fig. 5 と同様に圧縮力 が大きくなると実験值との間に多少のズレが生ず るが，ほぼよい一致を示しているといえる。さら に, このせん断力に対しては $P=7.5 \mathrm{kN} / \mathrm{m}$ のと き, 接触圧 $q$ は $\xi=-1$ で負になり浮き上がり状 態に入ることが示されている.

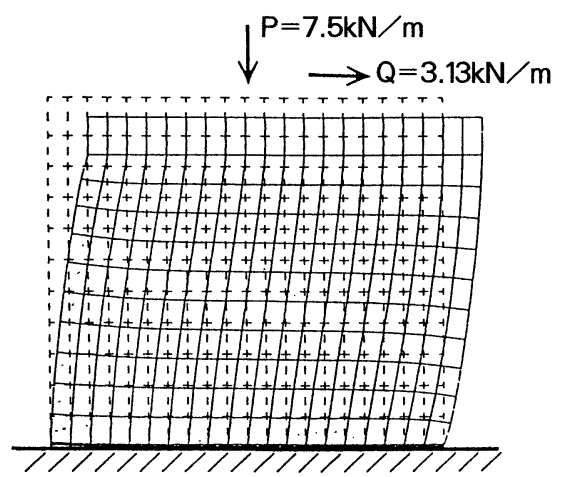

Fig. 2 Deformed configuration of tread rubber block calculated by finite element method, when $P=7.5$ $\mathrm{kN} / \mathrm{m}$ and $Q=3.13 \mathrm{kN} / \mathrm{m}$

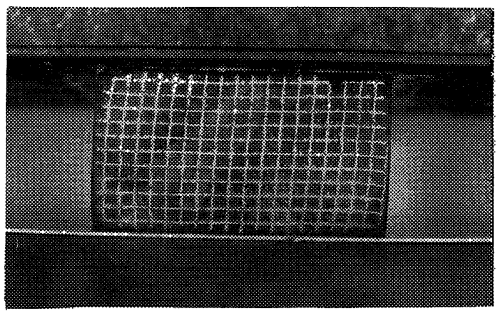

( a )

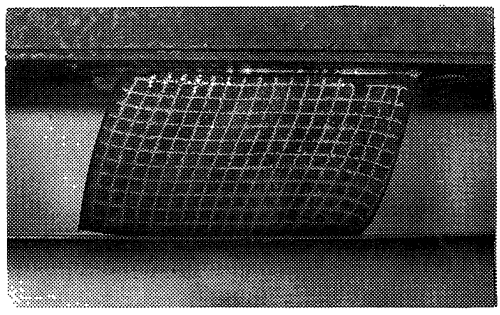

( b )

Fig. 3 Deformation of rubber block model with shape factor $s=0.667$, (a) prior to detaching under $P=10$ $\mathrm{kN} / \mathrm{m}$ and $Q=0$, (b) after detached under $P=10$ $\mathrm{kN} / \mathrm{m}$ and $Q=4.83 \mathrm{kN} / \mathrm{m}$

Fig. 7 は, 圧縮力 $P$ を一定として, せん断力 $Q$ を増加させたときの浮き上がり側接触端 $(\xi=-1)$ に打ける接触圧 $q$ の低下傾向を示したも 


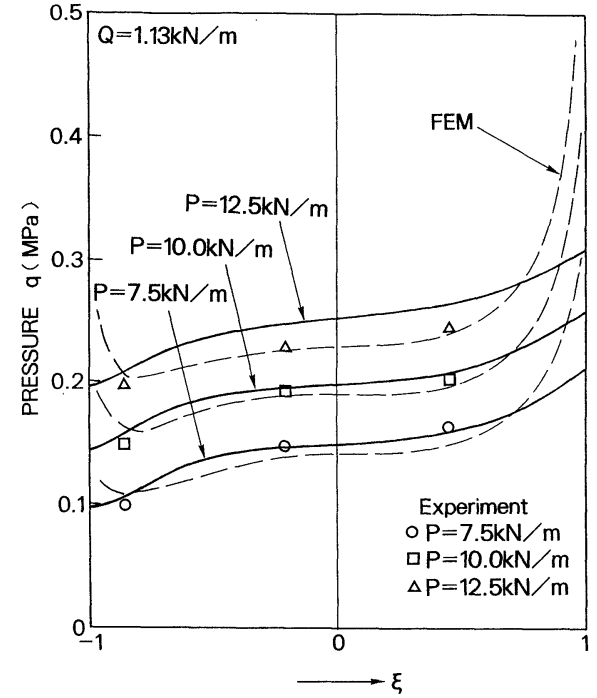

Fig. 4 Contact pressure distributions of rubber block with shape factor $s=0.625$ under $Q=1.13 \mathrm{kN} / \mathrm{m}$ and various values of $P$, comparing with experimental points and results by flnite element analyses

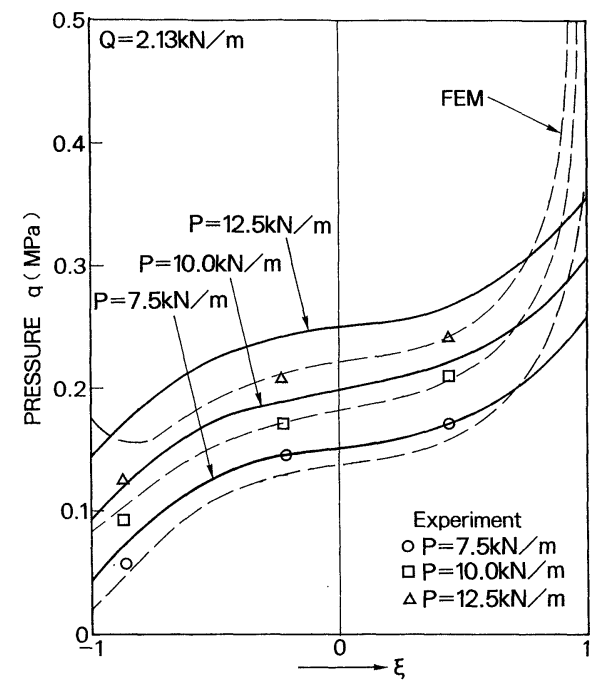

Fig. 5 Contact pressure distributions of rubber block with $s=0.625$ under $Q=2.13 \mathrm{kN} / \mathrm{m}$ and various values of $P$

のである．実験値と解析結果はお括むねよい一致 を示しているが，接触圧がゼロに近くなると多少 のズレが生ずる．この理由としては，せん断力が 増加してゴムブロックが浮き上がる間際では, 圧

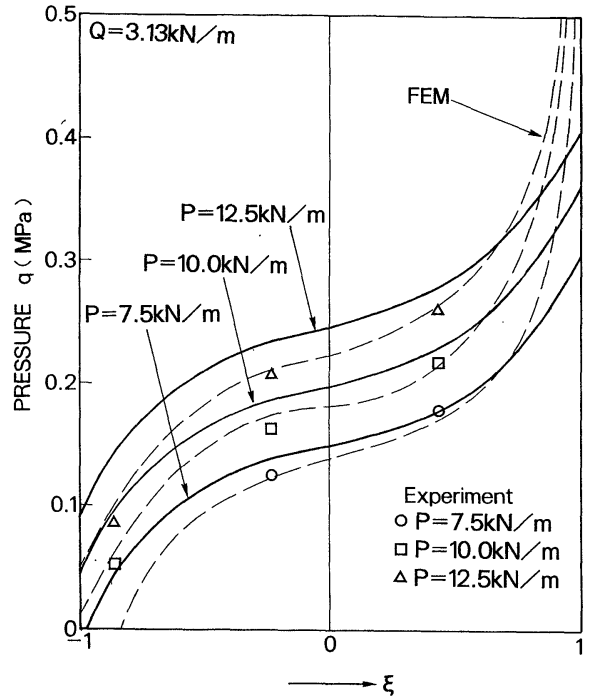

Fig. 6 Contact pressure distributions of rubber block with $s=0.625$ under $Q=3.13 \mathrm{kN} / \mathrm{m}$ and various values of $P$

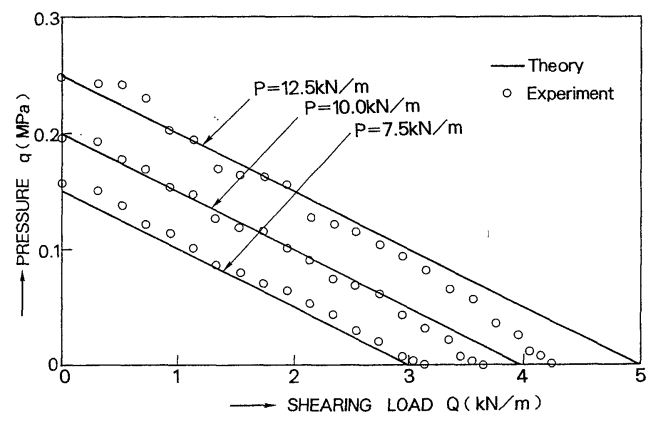

Fig. 7 Variation of contact pressure at $\xi=-1$, of rubber block with $s=0.625$ due to shearing force $Q$ under various values of $P$, comparing with experimental points

カセンサーに対して接触圧は斜めにかかってしま い実際の圧力ょり低い值を検出してしまうためと 考学られる．ここで，接触圧 $q$ がゼロとなるとき のせん断力を $Q_{c r}$ (浮き上がり限界せん断力) とす る.

Fig. 8 は，浮さ上がり限界せん断力 $Q_{c r}$ と圧縮 力 $P$ との関係を示した図である。 $Q_{c r}$ と $P$ は線形 関係になっている. 解析結果と実験值は概ね一致 しているが，多少の差異が現れた理由は先ほどの 説明と同様に圧力センサーの設置位置, およびセ 


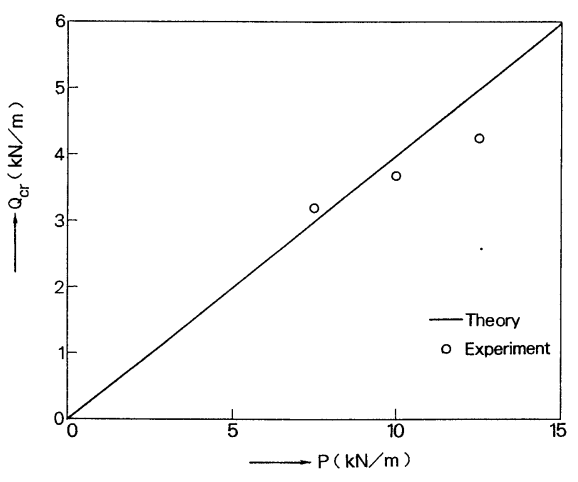

Fig. 8 Relationship between the critical shearing force, $Q_{c r}$, and the compressive force, $P$, comparing with experimental points

ンサーにかかる荷重の不均一化等によるものと思 われる。

$\xi=1$ における接触圧 $q$ が FEM 解析で高い值を とるのは, 本来ゴムの圧縮側における剛性が非線 形的に高くなる事実によるものと思われる。

Fig. 9 に接触面 $y=0$ に抢けるせん断応力の分 布を示した。

\section{4. むす び}

トレッドゴムブロックの圧縮せん断変形と接触 圧分布について，エネルギー法による近似解析を 行い, 以下の結論を得た。

（1）圧縮力 $P$ とせん断力 $Q$ の組み合わせ負荷 状態に対する接触部の圧力 $q$ 分布の近似表式を 導いた。この $q$ 分布は, FEMによる解析およ び実験值とよく一致することが確かめられた。

（2）ゴムブロックが圧縮力 $P$ を一定に保ち， $Q$ を増加させると, ブロック端の浮き上がり現象 が起こる. その時の限界せん断力 $Q_{c r}$ は $P$ に比 例する。

（3）高い接触圧を受ける側 $(\boldsymbol{\xi}=1)$ の接触圧 $q$ が FEM 解析結果と著しく異なるのは, 本解析で

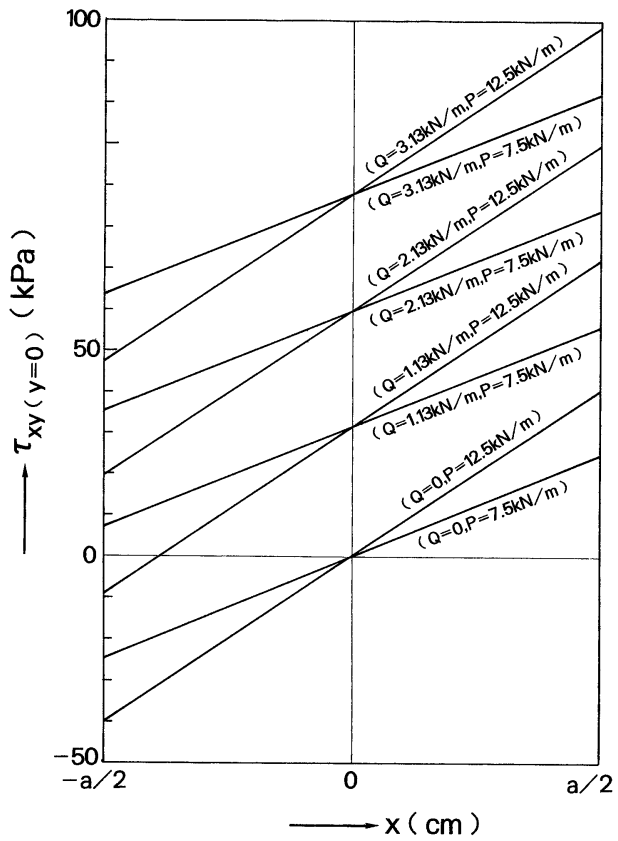

Fig. 9 Distributions of contact shearing stress, $\tau_{x y}$, for various coupled loading of $P$ and $Q$

材料の非線形性を考慮しなかったためであると 思われる. このことは, 直接浮き上がり現象に はほとんど影響しないが，強度上重要な意味を もつ. この非線形効果を考慮した近似解析を求 めることを今後の課題とする.

[付記]本論文は，1992年年次大会・研究発表講演 会にて発表したものである.

\section{参 考 文 献}

1) Akasaka T., Kabe K., Koishi M. and Kuwashima H.: Analysis the Contact Deformation of Tread Blocks, Tire Science and Technology, 20(4), 1992, 230p. 


\title{
THE CONTACT PRESSURE DISTRIBUTION AND DETACHING PHENOMENON OF TIRE TREAD RUBBER UNDER COM- PRESSIVE AND SHEARING FORCES
}

\author{
Takashi AKASAKA, Shigeru KAGAMI, Atsushi HASEGAWA and Hitoshi SHIOBARA \\ (Department of Precision Mechanics, Faculty of Science and Engineering, Chuo
} University 1-13-27 Kasuga, Bunkyo-ku, Tokyo 112)

The tire structure is forced usually to deform complexly and seriously on the roadway, to realize the fundamental performances of automobiles of running, turning and braking. The tread rubber block, as a constituent element of tire, plays an important role of holding the frictional forces between the tire and the road, for enabling car steering and breaking.

While the tread rubber block is subjected to compressive and shearing forces in contacting with the roadway, a phenomenon of the block edge detaching takes place, which leads to the contact area reduction and further the tread rubber wear.

An experimental study and a numerical analysis by using the finite element method based on a nonlinear elasticity law given by Mooney-Rivlin, have been conducted previously on this phenomenon, with predicting good agreement between them on the contact pressure distribution.

In this paper, an approximate analysis is presented on the contact deformation of a rubber block under compressive and shearing forces, by using the energy method based on the linear Hooke's law with considering the incompressibility of rubber, to reveal the critical condition of the detaching phenomenon. Good agreement is obtained among these analytical, numerical and experimental results for contact pressure distribution and detaching condition.

(Received in September 17, 1992) 